\title{
O papel do mouse, do game e da animação em Meu tio matou um cara: a geração digital e o culto ao presenteísmo
}

\author{
Denize Correa Araujo ${ }^{1}$ \\ Universidade Tuiuti do Paraná
}

\begin{abstract}
Resumo: A proposta deste artigo é dupla: em sentido mais amplo, analisar a representação da nova geração, tendo como embasamento teórico os conceitos da trivialidade da essência (Jameson) e do presenteísmo (Maffesoli); como objetivo mais específico, analisar o papel do mouse, do game e da animação no longa de Jorge Furtado Meu tio matou um cara (2004). Serão enfatizados o uso do virtual na construção da "cena do crime", o desempenho do mouse implícito do protagonista e a estrutura de videogame que perpassa o texto, criando imagens híbridas. Tanto na reconstrução do crime como na seqüência de fotos que provariam a traição da namorada de seu tio, o protagonista, em seu enfoque de adolescente, imagina estar jogando um videogame no computador. Seu mouse parece querer clicar em ícones $e$ abrir janelas a qualquer momento. A representação da interação dos três elementos-mouse, game e animação-retira do contexto o peso conteudístico do tema, que fica reduzido a um exercício de pseudo-detetive, e expõe, em primeiro plano, o universo juvenil, com sua familiaridade em interagir com games. O computador, além de suporte, é elemento essencial na vida da geração "clic-link" e ocupa lugar de destaque como coadjuvante do protagonista.

Como referencial teórico, serão usados os conceitos de Vicente Gosciola relacionados aos roteiros nas novas mídias, comentários de Steven Johnson sobre benefícios dos videogames, e as idéias de Scott McCloud quanto à estética do desenho animado e sua relação com os conceitos de verossimilhança, representação e referencialidade, além dos já citados conceitos de Jameson e Maffesoli.
\end{abstract}

Palavras-chave: geração digital, presenteísmo, trivialidade da essência, "estética so what"

$1 \mathrm{PhD}$ Literatura Comparada, Cinema e Artes (University of California, Riverside, 1998). Coordenadora do Mestrado em Comunicação e Linguagens e da Pós em Cinema (Universidade Tuiuti do Paraná). 
Meu tio matou um cara, longa de Jorge Furtado (2004) que retrata o presenteísmo (Maffesoli) da geração digital e a trivialidade da essência (Jameson) característica da contemporaneidade, enfatiza o papel do computador e seus componentes, capazes de colocar em segundo plano o pathos do tema e evidenciar a influência das assim chamadas "novas tecnologias".

A proposta mais ampla deste trabalho é verificar como a hibridação de elementos de mídias diversas pode caracterizar e representar o que Jameson define como trivialidade da essência na cena pós-modernista, Maffesoli classifica de presenteísmo, e eu denomino de estética "so what", ou seja, "e daî?", considerando que os diálogos e o contexto do filme retratam o fato principal, a ação, de maneira casual, continuando suas atividades cotidianas, como estudar, jantar, ver televisão. Como objetivo específico, ressalto que o filme destaca a presença do computador, não só como suporte ou ferramenta, mas como mediador ativo na vida da nova geração, além de coadjuvante do personagem central da narrativa do filme.

Jameson contrapõe a trivialidade característica do Pós-Modernismo à seriedade trágica do Modernismo, caracterizando o pastiche como uma prática neutra sem o sentido da paródia modernista, que tinha objetivos e convicções, refletindo, porém, que ambas as posições, seja a de condenar moralmente a trivialidade do pós-modernismo justapondo-o à seriedade do Modernismo, seja a de glorificar o presente em detrimento do passado ou vice-versa, são radicalismos que devem ser evitados:

...it is only consequent to reject moralizing condemnations of the postmodern and of its essential triviality when juxtaposed against the Utopian "high seriousness" of the great modernisms: judgements one finds both on the Left and on the radical Right. (Jameson, 46)

Sem glorificar o passado ou o presente, Meu tio matou um cara retrata o perfil que identifica o adolescente adaptado ao seu tempo, nascido na era digital, parte de um sistema de signos que se pautam na esfera computacional, no hibridismo das mídias, e na aceitação do game e do lúdico como parte de sua cotidianeidade. Se a essência foi trivializada, se a paródia se transformou em pastiche, se o culto ao passado cedeu seu lugar ao culto ao presente, Duda é a personificação desta reconfiguração, com seu modo digital de resolver 
os problemas reais, com sua inserção social, racial e sexual, com seu raciocínio veloz baseado em hipóteses hipertextuais que se transformam em conclusões.

Os conceitos de "trivialidade da essência" e "estética so what" convergem no que se refere à casualidade na cena contemporânea ao tratar de temas que requerem um tratamento mais profundo, como se a banalização do fato fizesse com que este passasse a não existir, ou a ser secundário. Por outro lado, a representação da geração presenteísta ocorre exatamente através da exposição explícita das possibilidades que o mouse, o game e a animação podem oferecer, seja no aspecto lúdico, seja na desreferencialização decorrente das mídias digitais. O filme, contudo, não banaliza e sim representa o que está sendo banalizado e trivializado nas novas gerações.

A representação da cena do crime, que é em animação, nos é mostrada através de um videogame. A câmera, simulando um cursor, e nós com ela, entramos na casa, e um mouse implícito fotografa, clica os objetos importantes e os arquiva, como evidências do crime. Esta é a única representação que temos da cena do crime. Por ser em cartoon, fica literalmente desreferencializada, fazendo com que a morte perca sua aura, trivializando a idéia de crime, de morte, de arma, enfim, de todo o aparato que compõe o momento trágico.

Ciro Marcondes Filho comenta que

quando a morte perde sua eficácia simbólica, seu efeito de choque, sua radicalidade sobre a vivencia cotidiana, toda a cultura perde, ao mesmo tempo, o componente trágico (a seriedade). A banalização da morte evoca o comportamento irônico-humorista, cínico, que se vê em todos os espaços outrora tidos como sérios (jornalismo, política, ciências). (51)

O elemento mais marcante da cena do crime é o uso da animação, que retira o pathos e remete ao lúdico, ao fictício, ao performático. O corpo não está ali e sim um desenho de onde deveria estar, um corpo desenhado graficamente, sem referências, aludindo ao título, à morte de "um cara".

O teórico Scott McCloud diz que imagens são informação recebida, mensagem instantânea e o texto escrito é informação percebida, observada, mensagem que deve ser decodificada. Se, por um lado, imagens não necessitam de conhecimento formal para 
serem entendidas, textos escritos requerem tempo no processamento dos símbolos abstratos da linguagem. Quando as imagens são mais abstratas, elas requerem maiores níveis de percepção. Quando as palavras são escritas em letra grande, diretas, requerem menos níveis de percepção e se aproximam das imagens.
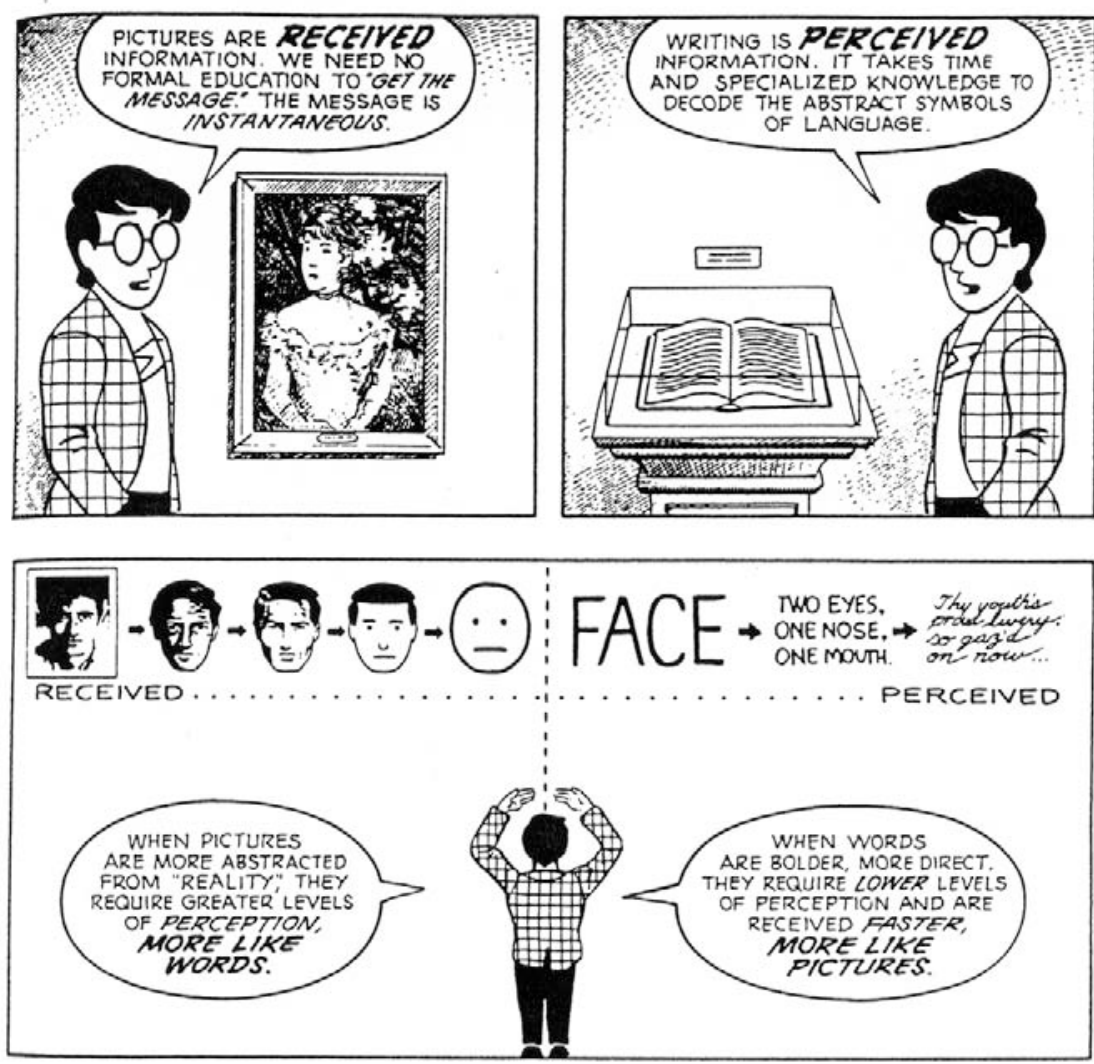

Fonte: Understanding Comics: The Invisible Art (Northampton, MA: Kitchen Sink, 1993) 49.

Understanding Comics $\mathbb{C}$ and tm Scott McCloud.

Eu diria que na animação, onde os objetos são simplificados, geometrizados, a cena fica distante de nós, emocionalmente. Um exemplo disso é o curta Almas em Chamas (Arnaldo Galvão, 2000) , que mostra cenas de sexo que, filmadas com atores reais, seriam consideradas pornográficas. O mesmo se pode dizer em relação ao curta Amassa que elas gostam (Fernando Coster, 1998), feito com bonecos de massinha. A animação faz com que os traços se assemelhem a personagens reais, mas se distanciem dos mesmos por sua simplificação genérica, que parece simular o que todos conhecemos como partes do corpo 
humano indiferenciadas. Quanto menos detalhes, mais impessoal a cena fica, quase que virtual, plástica, refratária. O diagrama de McCloud separa o lado esquerdo, onde a verossimilhança inicia com uma imagem completa e gradualmente retira os detalhes, do lado direito, onde palavras substituem imagens, indo de letras maiúsculas até descrições abstratas.

Em Meu tio matou um cara, se o corpo realmente estivesse exposto, o tom ficaria dramático. O impacto da animação para representar a cena do crime, pelo contrário, pode ser classificado como virtual, pelo seu distanciamento emocional, pela sua impessoalidade e, até mesmo, por uma certa objetividade em termos de configuração espacial.

Outro elemento que minimiza a presença da morte e do crime é a sua recomposição pelo personagem principal. Duca é o detetive que estuda as possibilidades. O filme parece se passar todo em um computador e é justamente esta técnica que inova a linguagem narrativa, o enfoque que simula links e sugere ao espectador uma quase que participação, uma motivação para acompanhar os links e clics do protagonista, que entra e sai do "real" até sem perceber, pois essa hibridação parece ser natural para ele. Assim como se percebe a familiaridade de Duca com esse real-irreal, fica evidente também a associação de duas mídias_ - c cinema e os games_que interagem continuamente, como se o filme se transformasse em uma grande tela de jogo eletrônico do gênero detetive. Na verdade, o jogo serve como mediador entre o assassinato real e as conclusões que Duca procura.

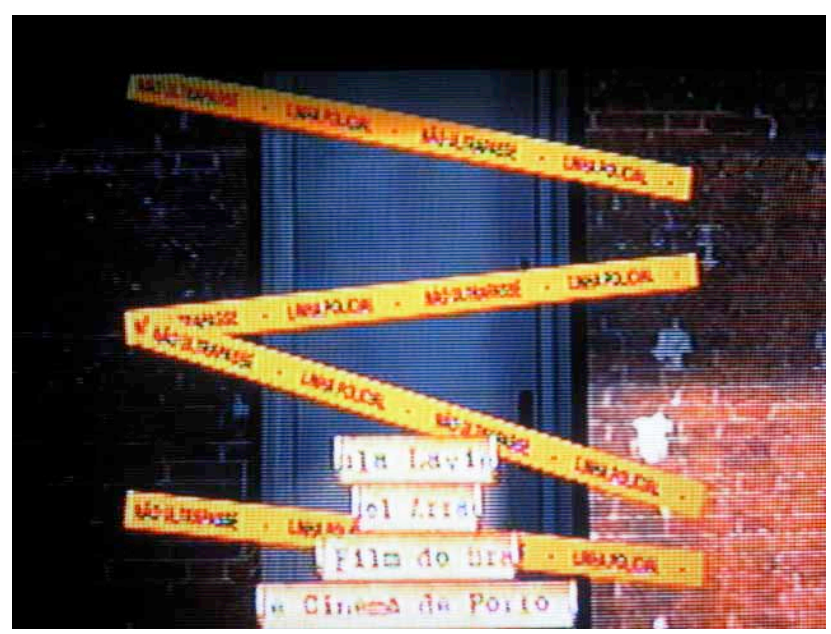


Simulando estar jogando um game, Duca analisa a hipótese de seu tio não estar dizendo a verdade, que para ele seria a de que seu tio, para proteger sua namorada, havia dito ter sido ele quem havia matado um cara quando na verdade havia sido ela. Mentalmente, Duca está sempre analisando, tirando fotos, abrindo janelas e arquivos, como se sua mente fosse um computador.
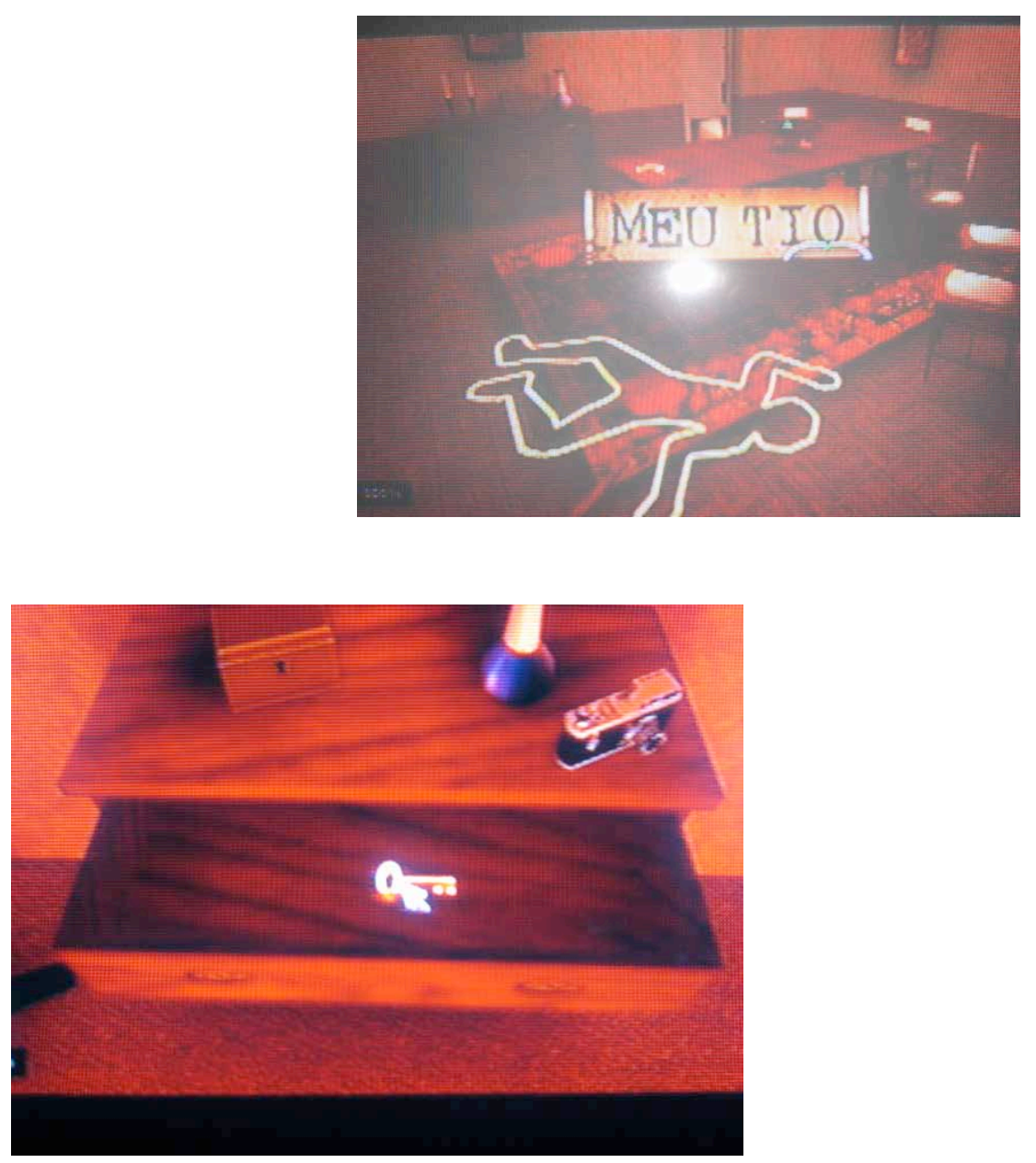

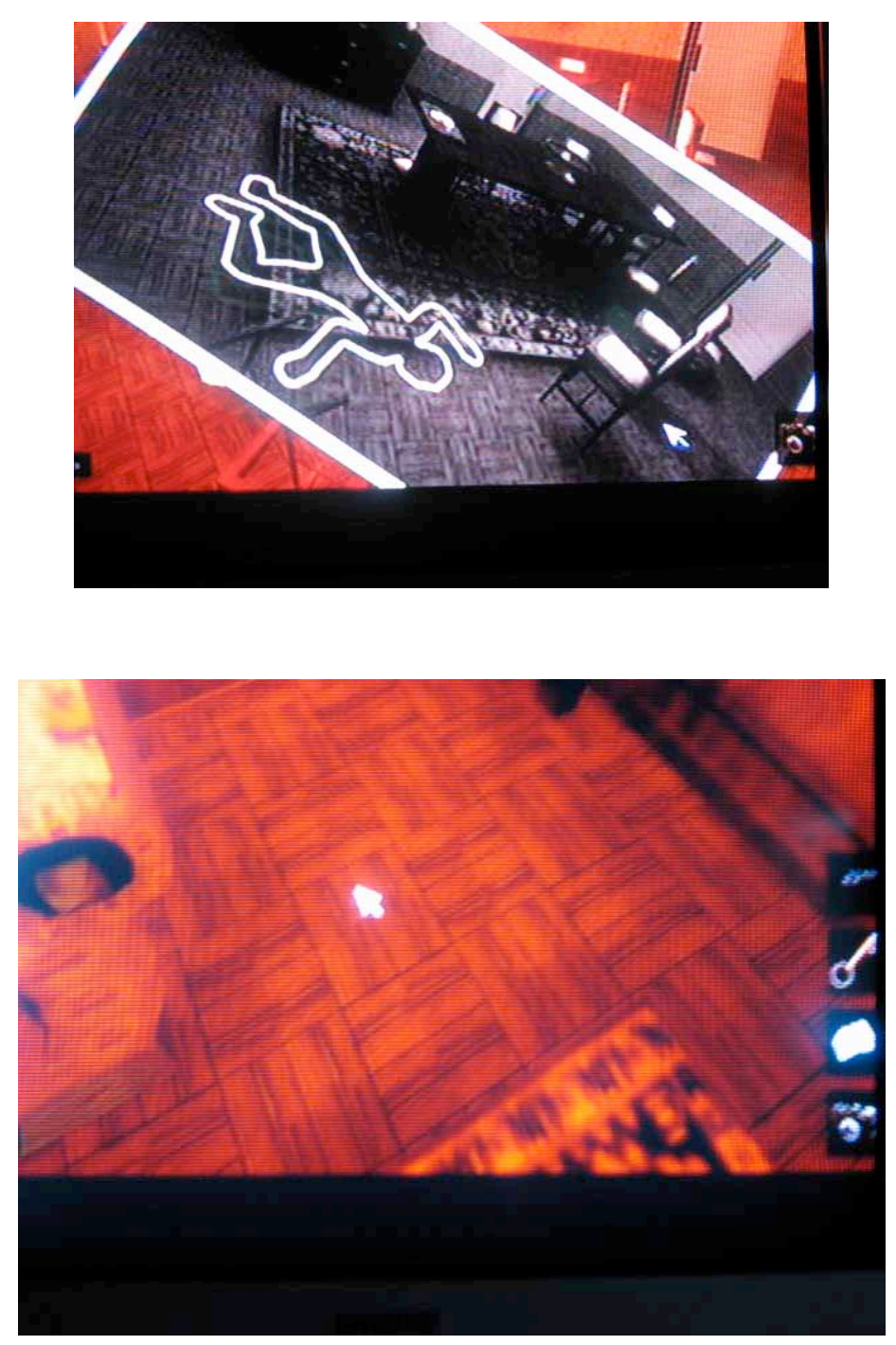

Sherry Turkle, Diretora do MIT, explora o modo como as pessoas utilizam os computadores e os efeitos dessa interação na construção da identidade. Para ela, as “janelas” são como metáforas para se pensar no self. "O "eu” não é mais simplesmente experimentar diferentes papéis em diferentes situações em diferentes lugares. A práticas das “janelas" (no mundo virtual) é a de um "eu” descentrado que existe em muitos mundos e que experimenta muitos papéis ao mesmo tempo. Turkle acredita também que os MUDs reduzem as fronteiras entre o "eu" e o jogo, o "eu" e o seu papel, o "eu" e a simulação (2002). 
Duca, ao investigar o caso de seu tio, está também experimentando suas habilidades, checando suas hipóteses e vivenciando o virtual no real. Turkle acredita que "estamos cometendo um grande erro em falar sobre vida real e vida virtual, como se uma fosse real e a outra não". (289). Segundo a autora, se considerarmos que as pessoas e, em nosso caso, os adolescentes passam cada vez mais tempo em lugares virtuais, as fronteiras entre o físico e o virtual se tornam cada vez mais permeáveis. Ela acredita que, para muitas pessoas, a virtualidade permite expressar os muitos aspectos do eu mais livremente. No caso em questão, o argumento faz sentido, considerando que Duca compartilha parte de seus pensamentos com as atividades virtuais, os computer games, que incentivam sua mente a reagir em situações reais.

Ao visitar o apartamento da namorada de seu tio, Soraia, Duca desvenda o segredo da namorada Soraia e de seu amigo Kid através da análise das fotos, o que o leva a confirmar sua hipótese sobre quem matou o cara. A sequência de fotos, rapidamente elaborada por Duca em formato de game, revela o que Soraia quer esconder. "Se ela mente sobre um assunto, com certeza faz o mesmo em outras situações”, é a conclusão de Duca.

O lúdico nem sempre é só entretenimento e perda de tempo. Há também uma parcela de transferência de aprendizado que pode resultar em conhecimento prático. Turkle sugere que o ciberespaço está oferecendo um lugar para esse tipo de "brincadeira", uma oportunidade para experimentação que não se encontra em outros contextos (292).

Um estudo conduzido por dois pesquisadores do Departamento de Ciência da Computação e do Laboratório Europeu de Mídia do Trinity College Dublin, David Coyle e Mark Matthews, comprovou que o game 3D "Personal Investigator" pode servir como substituto ou complementar ao tratamento psicoterápico:

By achieving the goals set by the game, teenagers learn to classify their problem, convert their problem to a goal and identify the resources they have to help them achieve this goal... Computer game is a powerful medium because it is an accepted part of teenage culture.

(http://medialabeurope.org/mindgames/publications/personalinve stigatorcH2004Presented.pdf)

(atingindo os objetivos do jogo, os adolescentes aprendem a classificar seus próprios problemas, convertendo-os em objetivos e identificando os recursos disponíveis para ajudá-los a alcançar suas 
metas... Os jogos de computador são um mídia poderosa por ser parte já aceita da cultura do adolescente).

Como o filme é conduzido por Duca que, como um narrador onisciente, nos mostra suas técnicas, ficamos cientes de sua metodologia de investigação, e sua procura de dados para justificar sua hipótese principal. Para completar sua conclusão, há também uma cena de hipertexto, quando Duca visualiza seu tio saindo de casa e esbarrando em uma senhora, que imediatamente o aponta como culpado. Em seguida, imagina outra situação onde o culpado é outro. Esta hipertextualidade manqué intensifica a relativização e subjetividade em torno das hipóteses sobre o ocorrido.

Se o hipertexto pode ser visto como simultaneidade, pode também ser lido como possibilidades, hipóteses, que parece ser o caso do filme em questão. Em sua análise, Duca considera algumas alternativas, e tenta provar suas investigações até chegar a ter certeza do culpado. Produto da geração digital, ou "geração clic-link", como eu a classificaria, Duca segue seu raciocínio de detetive. Contudo, mais importante do que a ocorrência em si é o que será dito sobre ela, a recomposição da cena, o impacto que ela terá sobre sua namorada, seus amigos, sua escola.

Aqui temos, então, a representação da socialidade do protagonista, o sentido da tribalização, a aceitação do grupo, o conceito de comunicação e informação. "Comunicação e informação descrevem um modus vivendi característico da pósmodernidade", diz Maffesoli (21-22), "a comunicação, antes de tudo, remete ao estar-junto; a informação, ao utilitário" (22), continua o autor, enfatizando que a noção de comunicação está implícita na socialidade: o indivíduo em relação aos outros. "As pessoas não querem só informação na mídia, mas também e fundamentalmente ver-se, ouvir-se, participar, contar o próprio cotidiano para si mesmas e para aqueles com quem convivem... o essencial está em reconhecer-se, em ver-se, em fazer parte de uma comunidade presencial ou virtual" (Maffesoli 23-24).

A informação fornecida casualmente por Duca, de que seu tio havia matado um cara, não tem o peso trágico da morte em si, mas forma um elo de ligação entre os participantes, quase como o desenrolar de uma novela, na qual cada capítulo provoca uma 
comunhão de idéias, um pertencer associado a um determinado grupo, que se sente participante do processo.

Maffesoli, em Religação Imaginal, sugere:

A socialidade do "mundo da vida" (Lebenswelt) não pode ser deduzida do social por um simples raciocínio lógico. Ela se assenta sobre a partilha das imagens, retomando esta expressão que, segundo Max Weber, caracteriza a comunidade, o que está em jogo é da ordem do emocional. A emocionalidade escapa da injunção moral. Tem uma base "ante-predicativa", pré-categorial. Vive-se a teatralidade corporal no cotidiano em rituais como a maneira de se vestir ou em expressões extremas como nas inúmeras "paradas" urbanas que evidenciam uma "ordo amoris" (Max Scheller) na qual predomina um forte sentimento de pertença. O ideal comunitário necessita de símbolos exteriores, de imagens compartilhadas para traduzir a força que internamente o estrutura. (250)

O triângulo Duca-Isa-Kid se faz, se desfaz e se refaz temporariamente, dependendo da situação de envolvimento no caso do assassinato, que na verdade é um pretexto para que Duca possa demonstrar suas habilidades detetivescas. Se Duca conta algo só a Kid, Isa se ressente, e vice-versa. Os três adolescentes entram e saem da rede com a mesma facilidade com que tecem comentários sobre o caso, ao mesmo tempo em que jantam, assistem televisão ou preparam seus deveres escolares: é a estética do "e daí?". Se o tio matou alguém, o fato não é tão significativo quanto o envolvimento dos personagens, que vão à prisão como se fossem a um museu ou um parque. Tudo parece perder o peso. Quando a mãe de Duca o adverte que a ida à prisão é perigosa, parece que está só desempenhando sua função de avisar, sem realmente pesar as conseqüências e sem proibir ou refletir seriamente sobre os possíveis problemas envolvidos. Tudo parece pertencer à esfera do superficial, as conversas dos pais sempre com a televisão como pano de fundo, os questionamentos de Duca mediados pelo uso do computador, os diálogos sintéticos na visita à namorada do tio, o aspecto fictício que a cena do crime provoca. $\mathrm{O}$ mérito do filme está justamente em representar esses aspectos em sua estrutura narrativa.

O filme implicita também o desenvolvimento emocional do protagonista, que usa o computador de forma bastante participativa. A pesquisadora Dulce Helena Penna Soares, Doutora em Psicologia Clínica na França, desenvolveu um estudo sobre a Internet como ferramenta para o desenvolvimento da identidade. Para ela, a Internet não é apenas 
tecnologia de comunicação e informação, mas também ferramenta para a expressão e transformação da identidade pessoal em seus múltiplos aspectos. A autora relata que "na perspectiva psicossociológica não é possível falar de identidade pessoal como uma entidade independente das relações sociais, pois ela depende do contínuo reconhecimento dos outros para se manter" (142).

Duca busca a aprovação de Isa e Kid, que também encontram na Internet um espaço de respostas e de interatividade. Tapscott acredita que a tecnologia, para os adolescentes, é tão simples quanto um videocassete ou uma torradeira elétrica, concluindo que a geração "net", como ele a chama, se desenvolverá através do uso da mídia digital (12). Se para a geração mais antiga a tecnologia certas vezes é fonte de questionamento e de polêmica sobre valores, para os jovens, ao contrário, é aceita naturalmente, como parte integrante da vida na escola, em casa e na sociedade.

Além do papel do computador e da animação, há no filme a presença enfática de uma imagem mental, revelada através de um mouse implícito, que clica, que aponta, que mostra as evidências, que sinaliza e detecta os problemas. Duca parece estar continuamente elaborando e seguindo os passos de uma roteirização. Vicente Gosciola, em seu livro Roteiro para as novas mídias: do game à TV interativa, explicita que cada tarefa "obriga a equipe, o autor, o roteirista ou o designer a pensar em links, isto é, em todas as etapas de conexão entre conteúdos" (237). Querendo resolver o caso, não tanto para o bem de seu tio (que considera um tolo), mas essencialmente para impressionar Isa, Duca vai armazenando informações, ligando fatos por analogia, provando que Soraia mente (em sua versão da seqüência de fotos na piscina), e que provavelmente envolveu seu tio em sua relação com o "cara”. Suas descobertas e evidências são hibridizadas no filme, por vezes coletadas de fatos reais, outras vezes recortadas de sua experiência em games, outras hipoteticamente construídas. O roteiro do filme, da mesma maneira, insere cenas de animação, mostra os protagonistas interagindo com games de computador, apresenta closes televisivos fragmentados, retrata o universo midiático e virtual onde os três adolescentes vivem. Sua ênfase e relevância, entretanto, não está nas técnicas de filmagem ou montagem e sim no modo como evidencia a importância do computador e seus componentes, não só como elementos passivos ou suportes, mas como protagonistas essenciais da mudança radical na 
apreensão do conhecimento e da reflexão de toda a geração contemporânea. A nãodramatização das emoções revela também a diferença entre duas gerações, não tão distantes cronologicamente, mas bastante diferenciadas em suas reações.

Segundo Gosciola, a interpretação menos teatral (mais contida) e menos narrrada é mais adequada à linguagem de hipermídia: "faz-se válida para a hipermídia a constituição da obra por personagens interpretados por pessoas, reais ou sintetizadas, que não utilizam a imposição dramática do teatro tradicional" (128). Embora a relevância do filme está mais em sua representação da nova geração do que em suas técnicas hipermidiáticas de produção e edição, estas estão presentes na caracterização do protagonista, através do qual nos são apresentados os fatos. Sabemos o que ele nos conta, e como ele nos conta. Ficamos conhecendo seu universo, interagindo com sua maneira de ver, de se expressar, de socializar e de pensar. Acompanhamos sua experiência em lidar com os problemas formatando-os como games.

Segundo Anderson, em seu livro O futuro do eu: um estudo da sociedade da pós-identidade:

os MUDs e os papéis eletrônicos têm a mesma função que um simulador de vôo, dando aos milhares e milhares de jovens, que neste momento estão improvisando e criando a si mesmos no espaço cibernético, um valioso treinamento para as existências que serão vividas em contextos múltiplos e sempre cambiantes. (2002, p. 131)

Se por um lado o filme retrata de maneira convincente o universo do adolescente, por outro sem dúvida fornece subsídios para um questionamento sobre as novas mídias e suas conseqüências. Para Dominique Wolton, a Internet "não passa de um sistema automatizado de informação"(149), que deve estar linkado a um conjunto de conhecimentos, a uma construção (150). Neste caso, qualquer mídia é igual, pois por mais interessante que os processos tecnológicos sejam, os conteúdos devem ser viabilizados pelos internautas, assim como em outras mídias analógicas, o que vai ao encontro do conceito de pastiche a que se refere Jameson: milhares de dados informacionais não chegam a constituir uma comunicação, um conteúdo, e continuam sendo um palimpsesto desordenado e sem significância, contribuindo para a trivialidade da informação, ou seja, dados efêmeros que servem para uma situação de momento, sem rastros históricos, sem 
perspectivas futuras. A geração presenteísta analisada por Maffesoli se caracteriza pelo prazer hedonista do momento, pelas emoções causadas pela velocidade dos meios de comunicação contemporâneos e pelo impacto espetacularizado e estetizante dos recursos tecnológicos.

Lucia Santaella, em relação à possibilidade de produção de imagens nesta era digital, se posiciona:

Nada pode mais deter o enxame de imagens triviais que passaram a povoar a vida de potencialmente cada vez mais pessoas, sem distinções de sexo, idade, classe e repertório cultural. Uma invasão inofensiva, mas, ao mesmo tempo, onipresente, paradoxalmente onipotente e sem importância. (200)

Talvez, por um ângulo mais extremista, esta seja uma leitura possível da cena contemporânea: uma invasão inofensiva de imagens, de informações, de dados estatísticos, de possibilidades de reprodução e envio de mensagens cada vez mais velozes, de interação espacial antes nunca presenciada, uma profusão de blogs e fotologs onipresente, "trivializando a essência", como Jameson diria.

Por outro ângulo mais neutro, poder-se-ia verificar até que ponto a geração net se diferencia do cartesianismo, da razão, do "penso logo existo", que hoje seria "clico logo existo", até que ponto os adolescentes vivenciam suas experiências de uma maneira diversa, expressando suas emoções mais livremente, resolvendo seus problemas online, em seus blogs, chat sessions, freqüentando lan houses para jogar seus computer games, enfim, exercitando virtualmente sua persona, seus avatares.

Steven Johnson, em seu livro Surpreendente! a televisão e o videogame nos tornam mais inteligentes, propõe uma reação aos inúmeros ensaios sobre a deteriorização da cultura popular, sugerindo que esta, ao contrário, ficou mais complexa e intelectualmente mais estimulante nos últimos 30 anos. O autor chama essa tendência ascendente de "Curva do Dorminhoco" baseada do filme Sleeper, de Woody Allen. Segundo Johnson, para compreender o novo é preciso livrar-se de conceitos mais antigos: mudanças básicas na tecnologia requerem novos tipos de entretenimento.

Não há nada mais convencional do que a sabedoria convencional que dizer que as crianças de hoje estariam em melhores condições 
se passassem mais tempo lendo livros e menos tempo fechando suas mentes em frente a seus videogames (p. 15)... hoje em dia, não tenho dúvidas de que jogar os videogames atuais realmente melhora a inteligência visual e a destreza manual, mas as virtudes dos jogos vão muito além da coordenação visual e motora (p. 20)

Para comprovar sua tese, Johnson cita o estudioso de jogos e $\mathrm{PhD}$ em Linguística James Paul Gee, que analisa o processo dos games em quatro ciclos, sondagem, hipótese, nova sondagem, novo pensamento, concluindo que, "quando os jogadores interagem com esses ambientes, estão aprendendo o procedimento básico do método científico" (p. 37).

Se a sinopse na capa do DVD de Meu tio matou um cara fornece poucos dados ao futuro espectador-- comédia romântica que descreve um adolescente de 15 anos que usa um episódio envolvendo seu tio, preso ao confessar ter matado um cara em nome do amor pela sua namorada, para conquistar sua colega de escola, que parece estar interessada em seu melhor amigo_o filme em si envolve muitos aspectos relevantes em sua temática atual. Ao retratar três adolescentes tentando entender a vida adulta, constrói um roteiro que privilegia o adolescente visto por ele mesmo, ao contrário do usual, que é o adolescente visto através do olhar do adulto.

Analisando as três características fundamentais de um roteiro (Gosciola, 131), ou seja, logos (a palavra que dá forma ao roteiro), pathos (promoção das emoções) e ethos (a moral, o que está implícito), veremos que a estética que predomina é a do "e daí?", uma visão adolescente da vida e dos relacionamentos, oriunda de um representante da nova geração, nascido sob a influência das novas tecnologias. Em roteiro híbrido, que oferece cenas mais cinematográficas, como a ida à prisão, e a busca da casa de Soraia, contracenando com outras mais hipertextuais, onde as possibilidades são montadas, modificadas, deletadas, em estrutura de game, e ainda com imagens captadas em $35 \mathrm{~mm}$ interagindo com DV (digital vídeo), em Meu tio matou um cara não há ênfase no melodrama (pathos) nem na moral implícita (ethos). Há, sim, uma tentativa de aproximação ao mundo linkado, ao universo teen, com sua cosmovisão, sugerindo uma representação que nos oferece elementos convincentes da geração digital, através do olhar arguto de um adolescente que interage com as chamadas novas mídias, tornando-as parte integrante de sua rotina, assim como da cotidianeidade de seus colegas. Sem considerar banais as 
experiências retratadas, que, na concepção jamesoniana poderiam ilustrar seu conceito da trivialidade da essência que caracteriza a pós-modernidade, o filme Meu tio matou um cara, mais ao molde de análise maffesoliana, procura entender o universo da geração digital.

\section{Referências:}

ANDERSON, Walter T. O futuro do eu: um estudo da sociedade da pós-identidade. São Paulo: Cultrix, 2002.

BANES, Sally. "Will the real... please stand up?” The Drama Review, 34.4 (1990).

CONNOR, Steven. Cultura Pós-Moderna. SP: Ed. Loyola, 1992.

COYLE, David e MATTHEWS, Mark. Personal Investigator: a therapeut 3D game for teenagers.

http://medialabeurope.org/mindgames/publications/PersonalInvestigatorCHI2004 Presented.pdf

GOSCIOLA, Vicente. Roteiro para as novas mídias: do game à TV interativa. SP: Ed. Senac, 2003.

JAMESON, Fredric. Postmodernism or, the cultural logic of late capitalism. Durham: Duke University Press, 1995.

JOHNSON, Steven. Surpreendente! a televisão e o videogame nos tornam mais inteligentes. Rio de Janeiro: Elsevier, 2005.

MARCONDES FILHO, Ciro. A Sociedade Frankenstein. www.eca.usp.br/nucleos/filocom/frank.doc

McCLOUD, Scott. Understanding Comics. Northhampton, Mass.: Kitchen Sink Press, 1993.

SANTAELLA, Lucia. Por uma epistemologia das imagens tecnológicas: seus modos de apresentar, indicar e representar a realidade. In Imagem (IR) Realidade: comunicação e cibermídia, org. Denize Araujo. Porto Alegre: Sulina, 2006, 173-201. 
SOARES, Dulce Helena Penna. A Internet como ferramenta para o desenvolvimento da identidade profissional. Psicologia em Estudo, Maringá, v. 8 n.2, 139-145, julho-dezembro 2003.

TAPSCOTT, Don. Geração digital: a crescente e irreversível ascensão da geração net. São Paulo: Makron Books, 1999.

TURKLE, Sherry. A memória na tela. In Memória Cotidiana: comunidades e comunicação na era das redes, org. Federico Casalegno. Porto Alegre: Sulina, 2006, 287-304.

---. "e-futures and e-personae". In Designing for a digital world. Ed. Neil Leach. London: John Wiley and Sons, 2002.

WOLTON, Dominique. Pensar a Internet. In A genealogia do virtual: comunicação, cultura e tecnologias do imaginário, orgs. Francisco Menezes Martins e Juremir Machado da Silva. Porto Alegre: Sulina, 2004, 149-156.

\section{Sites consultados:}

http://medialabeurope.org/mindgames/publications/PersonalInvestigatorCHI2004 Presented.pdf

www.eca.usp.br/nucleos/filocom/frank.doc 